\title{
University Students' knowledge, attitudes, and practices towards the National Premarital Screening Program of Saudi Arabia
}

\author{
Maryam A. Melaibari', Sireen A.R. Shilbayeh ${ }^{2}$, Abdulghani O. Kabli ${ }^{3}$ \\ Original IDepartment of Pharmacology, Faculty of Medicine, King Abdulaziz University, Jeddah, \\ Kingdom of Saudi Arabia
} Article

${ }^{2}$ Department of Pharmaceutical Practice, Faculty of Pharmacy, Princess Nourah Bint Abdul

Rahman University, Riyadh, Kingdom of Saudi Arabia

${ }^{3}$ Department of Medical Education, College of Medicine, Taif University, Taif City, Kingdom

of Saudi Arabia

\begin{abstract}
Background: There is an elevated rate of hereditary hemoglobinopathies in Arab populations. To address this, the Saudi government has implemented a mandatory premarital screening (PMS) program. Nevertheless, reports have shown that $48 \%$ of genetically incompatible partners have decided to marry. To address this, more information is needed on people's beliefs on these issues.

Aim: To investigate the knowledge, attitudes, and practices of Taif University students toward the national PMS program. Materials and Methods: Using a questionnaire, a cross-sectional study was conducted during April-May 2016 on a random sample of university students in Taif City. It was administered electronically and primarily distributed through the social media.

Results: Most participants (97.4\%) were aware that genes may transmit hereditary diseases and had heard about the PMS program. Most participants who partook in the PMS justified it based on preventing disease transmission to their offspring and ensuring their partner's health. A fair number (82.9\%) were willing to change their decision to marry in the case of receiving incompatible results. Moreover, the majority of the participants $(91.8 \%)$ demanded the implementation of a law that prohibits incompatible marriages.

Conclusion: Most Taif University students have a generally positive attitude and good intended practices toward PMS. However, targeted educational programs about the importance of PMS are strongly recommended to eliminate all factors that may affect the success of the PMS program.
\end{abstract}

Received: 12 November 2016, Accepted: 08 March 2017

Key Words: Consanguinity, hereditary hemoglobinopathy, marriage, premarital screening, reproductive health, Saudi Arabia sickle cell anemia, thalassemia.

Corresponding Author: Sireen A.R. Shilbayeh, MD, Department of Pharmaceutical Practice, Princess Nourah University, Riyadh, Kingdom of Saudi Arabia, Tel.: +966 557551 402,E-mail: sirraz_6@hotmail.com

ISSN: 0013-2446, Vol. 92, No.1

\section{INTRODUCTION}

Marriage is considered one of the most significant milestones in one's life. It is a cornerstone on which families and consequently communities are built. Marriage stability and success depend dramatically on partners' compatibility. The presence of hereditary or chronic communicable diseases can disrupt a marriage whether it affects the partners or their offspring. Thus, assurance of the partners' fitness before marriage via detection of those diseases and the likelihood of their presentation in their offspring is of crucial importance.

Hereditary diseases are considered as one of the most common causes of mortality and morbidity in infants and children $^{[1]}$. Hereditary hemoglobinopathies - especially sickle cell anemia and thalassemia - are the most prevalent hereditary diseases worldwide ${ }^{[2]}$. Unfortunately, the Arab population has an elevated rate of those diseases in comparison with other populations ${ }^{[3,4]}$. This is mostly due to the high rates of consanguinity, cultural restrictions, and due to lack of public health measures ${ }^{[5]}$.

There is a well-established relationship between hereditary diseases and consanguinity. Autosomal recessive inherited disorders have a high chance of developing in consanguineous marriages ${ }^{[3-6]}$. In the Arab population, consanguinity rate ranges from $10 \%$ in Morocco to more than $50 \%$ in Saudi Arabia ${ }^{[5]}$. Many cultural, traditional, social, and economic factors influence the preference of consanguinity in this population ${ }^{[5,7,8]}$.

The Kingdom of Saudi Arabia, a country with a 
population of $\sim 28$ million, is known for its high prevalence of hereditary hemoglobinopathies ${ }^{[6]}$. It is estimated that for every 10000 people in Saudi Arabia, there are 424 with sickle cell trait, 27 with sickle cell disease, 180 with thalassemia trait, and five with thalassemia disease ${ }^{[9]}$. These numbers along with the high rate of consanguinity have prompted the Saudi government to implement a mandatory premarital screening (PMS) program to protect future generations and ensure partner compatibility before marriage ${ }^{[10,11]}$.

In 2004, the Saudi National PMS Program started as a blood test for hereditary hemoglobinopathies, in particular; it aimed to detect sickle cell anemia and thalassemia ${ }^{[10]}$. In 2008, it was updated to include chronic communicable diseases, hepatitis $\mathrm{B}$ and $\mathrm{C}$ viruses, as well as $\mathrm{HIV}^{[12]}$. Even though the statistics show that Saudi Arabia has one of the lowest prevalence rates of hepatitis and HIV, this update was important to improving health education and clarifying unknown infection risks ${ }^{[13]}$.

Although the PMS is mandatory for every marriage in Saudi Arabia, partners have the right to marry regardless of the PMS results. Indeed, Alswaidi et al ${ }^{[14]}$ found that $88 \%$ of incompatible partners that were screened in 2005-2006 decided to marry. Later data reported a significant decrease in this rate to $48 \%$ by $2009^{[15]}$. This indicates that the screening program is likely highly effective in reducing atrisk marriages but there may be some cultural restrictions that need to be eliminated ${ }^{[15]}$.

Numerous studies have been conducted in Saudi Arabia to assess the knowledge and attitudes of university students toward the national PMS program ${ }^{[16-20]}$. However, none of them was conducted in Taif City or on its university students. This is an important group of the population as they are living in a Saudi region with a consanguinity rate of $55.9 \%{ }^{[21]}$. In addition, it was supposed that they ought to have adequate education and knowledge alongside their high probability to soon experience these issues as they are at an age that is considered highly eligible for marriage ${ }^{[2]}$.

The primary objective of this study is to explore the knowledge, attitudes, and practice of Taif University students toward the national PMS program of Saudi Arabia. This could help assess the efficacy of the PMS program in this region. Furthermore, it could provide guidance in determining the major cultural and traditional barriers that adversely affect the achievement of the PMS program goals.

\section{MATERIALS AND METHODS}

A questionnaire was developed based on the literature review of studies using the relevant questionnaires $^{[12,16,20,23,24]}$. It was piloted on 10 participants to examine its reliability and clarity. Accordingly, ambiguous and conflicting items were modified.

The final form of the questionnaire comprised four main sections and 36 close-ended items. The first section included sociodemographic data and history of hereditary diseases. The second section aimed to test the participant's knowledge concerning hereditary diseases and the PMS program of Saudi Arabia. The third section assessed the participant's attitude toward and perspective of the PMS program. The last section assessed the participant's degree of commitment to the PMS result in various scenarios.

The survey was conducted during April-May 2016. The target sample of 380 participants was estimated using the online EZSurvey software (Raosoft Inc., Seattle, Washington, USA, http://www.raosoft.com/samplesize. $\mathrm{html}$ ) with a $5 \%$ margin of error and $95 \%$ confidence level. All male and female students of Taif University from various colleges, except those in the pilot group, were included in the study. The sample was selected using the convenience sampling method. The questionnaire was administered electronically and distributed through the social media. The official twitter account for deanship of students' affairs in Taif University posted a tweet with our questionnaire link and encouraged students to participate. In addition, the link was broadcasted to 'WhatsApp' as almost every class of the university has a student group in this application. Responses were reviewed periodically during data collection to ensure that all participants are Taif University students. Responses from the faculty members or other Taif University employees were excluded. Once the target sample was reached, the questionnaire link was disabled.

\section{Statistical analysis}

All collected data were coded, entered, and analyzed using the statistical package for the social sciences software (version 23.0; IBM Corp., Armonk, New York, USA). Descriptive statistics (frequencies) were used to describe the sample characteristics.

\section{Ethical approval}

The Research Ethics Committee of Taif University granted approval to conduct this study in April 2016. The questionnaire was administered electronically and predominantly distributed via social media. It was emphasized that participation was optional and the confidentiality of the participant's information was assured

\section{RESULTS}

The sample consisted of 380 eligible participants. Almost all of them were Saudis (98.4\%) with an age range of 19-25 years. Approximately half of the participants $(48.4 \%)$ were men and half of them $(51.6 \%)$ were women. Only $6.6 \%$ of all participants reported a personal history of hereditary diseases, whereas $16.6 \%$ reported a family history of hereditary diseases. Half of them $(50.5 \%)$ had consanguineous parents and $77.1 \%$ of them were firstdegree relatives. The sociodemographic characteristics and history of hereditary diseases are, respectively, summarized in Table 1. 
Table 1A: Sociodemographic characteristics of Taif University Students, Taif City, KSA, 2016

\begin{tabular}{|c|c|}
\hline Characteristic & No. $(\%)$ \\
\hline \multicolumn{2}{|l|}{ Gender } \\
\hline Male & $184(48.4)$ \\
\hline Female & $196(51.6)$ \\
\hline \multicolumn{2}{|l|}{ Age } \\
\hline$<18$ & $20(5.3)$ \\
\hline $19-25$ & $301(79.2)$ \\
\hline$>25$ & $59(15.5)$ \\
\hline \multicolumn{2}{|l|}{ Nationality } \\
\hline Saudi & $374(98.4)$ \\
\hline Non-Saudi & $6(1.6)$ \\
\hline \multicolumn{2}{|l|}{ Family's monthly income } \\
\hline$<5000 \mathrm{SR}$ & $80(21.1)$ \\
\hline 5000- $10000 \mathrm{SR}$ & $137(36.1)$ \\
\hline $10000-20000 \mathrm{SR}$ & $113(29.7)$ \\
\hline$>20000 \mathrm{SR}$ & $50(13.1)$ \\
\hline \multicolumn{2}{|l|}{ Home/town } \\
\hline Taif & $315(82.9)$ \\
\hline Makkah & $15(2.6)$ \\
\hline Jeddah & $21(5.5)$ \\
\hline Taif Suburbs & $20(5.3)$ \\
\hline Others & $14(3.7)$ \\
\hline \multicolumn{2}{|l|}{ Marital status } \\
\hline Married & $76(20.0)$ \\
\hline Single & $302(79.4)$ \\
\hline Divorced & $1(0.3)$ \\
\hline Widower & $1(0.3)$ \\
\hline \multicolumn{2}{|l|}{ Academic year } \\
\hline 1 st year & $62(16.3)$ \\
\hline 2nd year & $38(10.0)$ \\
\hline 3rd year & $66(17.4)$ \\
\hline 4th year & $66(17.4)$ \\
\hline 5 th year & $50(13.2)$ \\
\hline 6th year & $98(25.8)$ \\
\hline \multicolumn{2}{|l|}{ College } \\
\hline Education & $33(8.7)$ \\
\hline Science & $52(13.7)$ \\
\hline Medicine & $106(27.9)$ \\
\hline Computer and IT & $13(3.4)$ \\
\hline Admins and financial & $44(11.6)$ \\
\hline Pharmacy & $23(6.1)$ \\
\hline Art & $12(3.2)$ \\
\hline Engineering & $13(3.4)$ \\
\hline Community and CE & $17(4.5)$ \\
\hline Health science & $9(2.4)$ \\
\hline
\end{tabular}




$\begin{array}{lr}\text { Al-sharia and regulations } & 15(3.9) \\ \text { Designs and home economics } & 21(5.5) \\ \text { Dentistry } & 9(2.4) \\ \text { Others } & 13(3.4)\end{array}$

SR: Saudi Riyals, IT: Information Technology, CE: Continuous Education

Table 1B: History of consanguinity and hereditary diseases of Taif university students, Taif city, KSA, 2016

\begin{tabular}{lc}
\hline Characteristic & No. $(\%)$ \\
\hline Parental consanguinity $(\mathrm{n}=380)$ & $193(50.8)$ \\
Yes & $187(49.2)$ \\
No & $148(76.7)$ \\
Type of consanguinity $(\mathrm{n}=193)$ & $45(23.3)$ \\
1st Relative & \\
2nd Relative & $1(0.3)$ \\
Personal history of hereditary diseases & $1(0.3)$ \\
Sickle cell anemia & $4(1.1)$ \\
Thalassemia & $19(5.0)$ \\
G6PD deficiency & $355(93.4)$ \\
Other & \\
None & $7(1.8)$ \\
Family history of hereditary diseases & $3(0.8)$ \\
Sickle cell anemia & $7(1.8)$ \\
Thalassemia & $46(12.1)$ \\
G6PD deficiency & $317(83.4)$ \\
Other & \\
None &
\end{tabular}

G6PD: Glucose-6-Phosphate Dehydrogenase Deficiency

Most of the participants $(97.4 \%)$ were aware that genes could transmit hereditary disease. Furthermore, the majority of them $(98.9 \%)$ had heard about the PMS program. In terms of knowledge of hemoglobinopathies, a high percentage of medical students (96.6 and 89.1\%) compared with nonmedical students (61.8 and 31.6\%) have heard about sickle cell anemia and thalassemia, respectively. Less than
$60 \%(58 \%)$ of the participants knew that PMS detects both hereditary and chronic communicable diseases. In contrast, $42.1 \%$ thought that PMS tested the participant's fertility and thus their capacity to have children. Among those, $55.6 \%$ were men and $44.4 \%$ were women. The results concerning the participants' knowledge is shown in Table 2.

Table 2: Knowledge of Taif university students about PMS, Taif city, KSA, 2016

\begin{tabular}{ll}
\hline Knowledge & $\%$ \\
\hline Hereditary diseases can be transmitted by genes & 97.4 \\
Heard of sickle cell anemia & 75.3 \\
Heard of thalassemia & 53.9 \\
Heard of PMS & 98.9 \\
PMS detects hereditary diseases only & 34.5 \\
PMS detects communicable diseases & 85.3 \\
PMS tests the ability to get children & 42.1 \\
\hline
\end{tabular}


Table 3 lists all attitudes, beliefs, and the degree of the participants' agreement to each one of them. The vast majority $(85.3 \%)$ of the participants generally agreed that consanguinity could increase the chance of hereditary diseases. However, $41.1 \%$ were unsure if they prefer consanguineous marriage or not. For most of the participants, the reasons for partaking in a PMS were to prevent disease transmission to the offspring (94.5\%) and to ensure the health of their partner (94.2\%). Remarkably, $36.1 \%$ strongly disagreed that the PMS could prevent disease transmission to them, whereas $29.2 \%$ reported being unsure.

Table 3: Attitudes, beliefs and motives of Taif university students towards PMS, Taif city, KSA, 2016

\begin{tabular}{|c|c|c|c|c|c|}
\hline Attitude and motives & 5 & 4 & 3 & 2 & 1 \\
\hline \multicolumn{6}{|l|}{ Attitude } \\
\hline I prefer consanguineous marriage & 8.2 & 26.1 & 41.1 & 41.1 & 11.3 \\
\hline Consanguinity can increase the chance of hereditary diseases & 50.3 & 35.0 & 12.1 & 12.1 & 0.0 \\
\hline Hereditary diseases have a psychological burden on families & 55.0 & 33.7 & 8.2 & 8.2 & 0.5 \\
\hline Hereditary diseases have an economic burden on families & 47.4 & 32.4 & 13.7 & 13.7 & 1.1 \\
\hline PMS does not interfere with a belief in destiny & 63.2 & 31.1 & 4.7 & 4.7 & 0.5 \\
\hline \multirow{2}{*}{\multicolumn{6}{|c|}{$\begin{array}{l}\text { Motives for carrying out PMS: } \\
\text { I will/was carry out PMS for the following motives: }\end{array}$}} \\
\hline & & & & & \\
\hline - to prevent disease transmission to offspring & 79.2 & & 15.3 & 4.7 & 0.3 \\
\hline - to ensure health of the partner & 68.9 & & 25.3 & 4.2 & 0.5 \\
\hline - to prevent disease transmission to me & 5.5 & & 9.7 & 29.2 & 36.1 \\
\hline - because I was obliged by law & 14.2 & & 20.8 & 29.7 & 17.6 \\
\hline \multicolumn{6}{|l|}{ I will/was not carry out PMS for the following motives: } \\
\hline - because I will marry my cousin any way & 5.8 & & 8.7 & 29.2 & 33.4 \\
\hline - because it may not be in favor of my choice & 72.4 & & 20.8 & 4.5 & 1.1 \\
\hline
\end{tabular}

$1=$ Strongly Disagree, $2=$ Disagree, $3=$ Unsure, $4=$ Agree, $5=$ Strongly Agree (in \%)

Regarding compliance to the PMS, only $23.4 \%$ reported they would decide to marry with the risk of hereditary diseases and $9.5 \%$ with a risk of communicable diseases. In contrast, $82.9 \%$ were willing to change their decision to marry in the case of a result demonstrating incompatibility. Most of the participants $(91.8 \%)$ reported that they would demand the implementation of a law that prohibits incompatible marriages. Participants' practices concerning PMS are shown in Table 4. 
Table 4: Intended practices of Taif university students, Taif city, KSA, 2016

\begin{tabular}{lc}
\hline Practice & $\%$ \\
\hline Will would carry out PMS & 95.3 \\
Decisions post-PMS & 23.4 \\
- Will $\backslash$ would decide to marry even if there is a hereditary disease risk & 9.5 \\
- Will $\backslash$ would decide to marry even if there is a communicable disease risk & 82.9 \\
- Willing to change decision to marry in the case of incompatibility & 91.8 \\
- Will demand implementation of a law that prohibits incompatible marriages & 92.9 \\
- Will contribute to raising awareness about the importance of PMS & \\
\hline
\end{tabular}

\section{DISCUSSION}

Detection of hereditary or communicable disease carriers to control prevalence is an acceptable international practice $^{[10]}$. It is also considered one of the most effective prevention strategies in highly consanguineous populations ${ }^{[11]}$. Thus, the implementation of screening programs like the national PMS program of Saudi Arabia is very important. It is also important to know the degree of this program's approval among university students to enhance its effectiveness and reach to this population.

As previously mentioned, Saudi Arabia has a reported consanguinity rate of more than $50 \%$ with a high prevalence of first-degree relative marriages ${ }^{[5]}$. This is consistent with the findings of the present study, $50.5 \%$ of the participants had consanguineous parents and $77.1 \%$ of them were firstdegree relatives. Ibrahim et al. ${ }^{[12]}$ reported a slightly lower consanguinity rate of $44.5 \%$ in a similar study targeted at attendees of governmental outpatient clinics in Jeddah. Ibrahim et al. ${ }^{[19]}$ also reported much lower rate (34.6\%) from students in King Abdulaziz University in Jeddah. This could be explained by the significant cultural and traditional variations between these two cities in Saudi Arabia.

This study showed that most of Taif University students knew that genes could transmit hereditary diseases and a fair number of them have heard about sickle cell anemia and thalassemia. In contrast, only $58 \%$ of participants knew that PMS detects both hereditary and chronic communicable diseases'. Furthermore, $42.1 \%$ thought it tested the fertility of participants. These results are consistent with other reports from different regions in Saudi Arabia. A similar study conducted in King Abdulaziz University, Jeddah, found that most of their students had sufficient knowledge about hereditary diseases in general, but they had inadequate knowledge of $\mathrm{PMS}^{[17]}$. Another study conducted in King Saud University, Riyadh, reported that $20 \%$ of university students had inadequate knowledge about $\mathrm{PMS}^{[20]}$. This is an indication of the need for PMS educational programs as well as genetic counseling programs targeting university students. Notably, Ibrahim et al. ${ }^{[19]}$ conducted a study to assess the knowledge and attitudes of unmarried female students in King Abdulaziz University, Jeddah, toward PMS before and after an educational campaign. They found that $80.9 \%$ of the sample had inadequate knowledge about PMS. Interestingly, this percentage significantly declined to $21.9 \%$ after attending an educational campaign about $\mathrm{PMS}^{[19]}$.

Recently, the PMS program has gained acceptance from the general population ${ }^{[25]}$. Many studies from different regions of Saudi Arabia agree to this. Al-Kaldi et al. ${ }^{[16]}$ reported $70 \%$ acceptance rate of the PMS program among health science students in Abha. Similarly, a study in King Abdulaziz University, Jeddah, reported that $99 \%$ of female students generally agreed on the importance of $\mathrm{PMS}^{[19]}$. In a community-based study conducted in Riyadh, 94\% considered PMS as an important preventive measure for a genetic blood disorder ${ }^{[24]}$. The current study also reported general positive attitude toward PMS among Taif University students.

PMS is carried out for several reasons. Most of this study's participants partook in the PMS to prevent disease transmission to their offspring and to ensure the health of their partner. One remarkable finding is that only a small portion agreed that they partook in PMS to prevent disease transmission to themselves. In contrast, the most common reason for PMS rejection for nearly all participants in this study was the fear of receiving incompatible PMS results and consequently the termination of an otherwise favorable marriage. Health Science students in Abha agreed to these same reasons with contradictory results. The prevention of disease transmission to them and their offspring was the primary reason for partaking in a PMS rather than to certify the health of their partners. In addition, their main reason for rejecting PMS was to not interfere with God's will ${ }^{[16]}$. Older studies reported the presence of misconceptions about Islamic principles that lead to PMS rejection ${ }^{[24]}$. Only $1 \%$ of participants in the present study had a religious misconception regarding PMS as they thought it interfered with their belief in destiny. Moreover, studies from Riyadh and Jeddah reported few students with similar misconception $^{[12,20]}$.

In this study, the majority (82.9\%) were willing to change their marriage decision in case of incompatibility. In Jeddah, $67.1 \%$ of unmarried female students in King Abdulaziz University were in favor of marriage cancellation when PMS results revealed a genetic disease ${ }^{[19]}$. In Riyadh, Al Sulaiman et al. ${ }^{[23]}$ also report that more than $60 \%$ of 
all participants from Riyadh believe that marriage plans should be canceled with a high risk of hereditary disease. These numbers reflect a significant improvement in the PMS program acceptance. However, the remaining percentages of those planned to continue incompatible marriages indicate the presence of cultural barriers that need to be addressed.

As mentioned previously, even if the PMS program is mandatory to get married, each partner is free to marry regardless of their test results. In the present study, most of Taif University students $(91.8 \%)$ are demanding the implementation of a law that prohibits incompatible marriages. In consistence, a study in Jeddah (2011) showed that $64.6 \%$ of female university students agreed that the decision to marry should be free regardless of the risk of hereditary disease ${ }^{[19]}$. Conversely, earlier reports from Riyadh showed a $63 \%$ approval rating in favor of legal interference in case of incompatibility ${ }^{[24]}$, whereas more recent reports have shown a far lower percentage, with only $36 \%$ participants, agreeing to implement laws and regulations to prevent at-risk marriages ${ }^{[20]}$.

\section{STUDY LIMITATIONS}

Convenience sampling was a clear limitation of this study. Some faculties were overrepresented as they accessed the link first, whereas others have much lower responses. Stratified random sampling would eliminate this problem, but it could not be done due to limited information about students' numbers in each faculty.

\section{CONCLUSION}

Most Taif University students have a generally positive attitude and reported good intended practices toward PMS. However, targeted educational programs that are concerned with the diseases are tested by PMS and how its results could affect their partners and offspring are strongly recommended to clarify any conflicts and eliminate any barriers that could affect the PMS program success.

\section{ACKNOWLEDGEMENTS}

The authors acknowledge all the research assistants' group including: Yousof O. Kabli (College of Medicine, King Abdulaziz University, Jeddah, Kingdom Saudi Arabia), Rayan A. Alsofyani, Abdullah S. Basaba, Mohammed A. Saif, Faisal E. Nahhas, and Abdulrahman S. Altalhi (College of Medicine, Taif University, Taif City, Kingdom of Saudi Arabia) for helping with data collection, entry, and analysis

\section{CONFLICT OF INTEREST}

There are no conflicts of interest.

\section{REFERENCES}

1. Christianson AL, Howson CP, Modell B. March of Dimes global report on birth defects: the hidden toll of dying and disabled children. Birth Defects Foundation; 2006.

2. WHO. Management of birth defects and haemoglobin disorders: report of a joint WHO-March of Dimes meeting. Geneva, Switzerland: World Health Organization; 2006.

3. Al-Gazali L, Hamamy H, Al-Arrayad S. Genetic disorders in the Arab world. BMJ 2006; 333: 831-834.

4. Teebi AS. Genetic disorders among Arab populations. Berlin; Heidelberg: Springer-Verlag; 2010.

5. Hamamy $\mathrm{H}$, Antonarakis SE, Cavalli-Sforza LL, Temtamy S, Romeo G, Ten Kate LP, et al. Consanguineous marriages, pearls and perils: Geneva international consanguinity workshop report. Genet Med 2011; 13: 841-847.

6. Al-Owain M, Al-Zaidan H, Al-Hassnan Z. Map of autosomal recessive genetic disorders in Saudi Arabia: concepts and future directions. Am J Med Genet A 2012; 158: 2629-2640.

7. Teeuw ME, Loukili G, Bartels EA, ten Kate LP, Cornel MC, Henneman L. Consanguineous marriage and reproductive risk: attitudes and understanding of ethnic groups practising consanguinity in Western society. Eur J Hum Genet 2014; 22: 452-457.

8. Warsy AS, Al-Jaser MH, Albdass A, Al-Daihan S, Alanazi M. Is consanguinity prevalence decreasing in Saudis? A study in two generations. Afr Health Sci 2014; 14: 314-321.

9. Memish ZA, Owaidah TM, Saeedi MY. Marked regional variations in the prevalence of sickle cell disease and $\beta$-thalassemia in Saudi Arabia: findings from the premarital screening and genetic counseling program. J Epidemiol Glob Health 2011; 1: 61-68.

10. El-Hazmi MA. The natural history and the national pre-marital screening program in Saudi Arabia. Saudi Med J 2004; 25: 1549-1554.

11. Meyer B. Strategies for the prevention of hereditary diseases in a highly consanguineous population. Ann Hum Biol 2005; 32: 174-179.

12. Ibrahim NK, Bashawri J, Al Bar H, Al Ahmadi J, Al Bar A, Qadi M, et al. Premarital Screening and Genetic Counseling program: knowledge, attitude, and satisfaction of attendees of governmental 
outpatient clinics in Jeddah. J Infect Public Health 2013; 6:41-54.

13. Alswaidi FM, O'Brien SS. Is there a need to include HIV, HBV and HCV viruses in the Saudi premarital screening programme on the basis of their prevalence and transmission risk factors? J Epidemiol Community Health 2010; 64:989-997.

14. Alswaidi FM, Memish ZA, O'Brien SJ, AlHamdan NA, Al-Enzy FM, Alhayani OA, et al. At-risk marriages after compulsory premarital testing and counseling for $\beta$-thalassemia and sickle cell disease in Saudi Arabia, 2005-2006. J Genet Couns 2012; 21: 243-255.

15. Memish ZA, Saeedi MY. Six-year outcome of the national premarital screening and genetic counseling program for sickle cell disease and $\beta$-thalassemia in Saudi Arabia. Ann Saudi Med 2011; 31: 229.

16. Al-Khaldi YM, Al-Sharif AI, Sadiq AA, Ziady HH. Attitudes to premarital counseling among students of Abha Health Sciences College. Saudi Med J 2002; 23: 986-990.

17. Al-Aama JY, Al-Nabulsi BK, Alyousef MA, Asiri NA, Al-Blewi SM. Knowledge regarding the national premarital screening program among university students in western Saudi Arabia. Saudi Med J 2008; 29: 1649-1653.

18. Al-Aama JY. Attitudes towards mandatory national premarital screening for hereditary hemolytic disorders. Health Policy 2010; 97: 32-37.
19. Ibrahim NK, Al-Bar H, Al-Fakeeh A, Al Ahmadi J, Qadi M, Al-Bar A, et al. An educational program about premarital screening for unmarried female students in King Abdul-Aziz University, Jeddah. J Infect Public Health 2011; 4: 30-40.

20. Khalil EMF, Abdelkader SM, Alsaeed MD, Alshahrany NM. Knowledge, belifes and behavior intention about premarital screening among King Saud University female students in Riyadh. Sch J Appl Med Sci 2014; 2(5E): 1797-1805.

21. El-Mouzan MI, Al-Salloum AA, Al-Herbish AS, Qurachi MM, Al-Omar AA. Regional variations in the prevalence of consanguinity in Saudi Arabia. Saudi Med J 2007; 28: 1881-1884.

22. Rashad H, Osman M, Roudi-Fahimi F. Marriage in the Arab world: Population Reference Bureau (PRB); 2005

23. Al Sulaiman A, Suliman A, Al Mishari M, Al Sawadi A, Owaidah TM. Knowledge and attitude toward the hemoglobinopathies premarital screening program in Saudi Arabia: population-based survey. Hemoglobin 2008; 32: 531-538.

24. Al-Kahtani NH. Acceptance of premarital health counseling in Riyadh city, 1417H. J Family Community Med 2000; 7: 27.

25. Abdel Meguid N, Zaki M, Hammad S. Premarital genetic investigations: effect of genetic counselling. East Mediterr Health J 2000; 6: 653. 